\title{
EFFECT OF PORE STRUCTURE ON SALT CRYSTALLIZATION \\ DAMAGE OF CEMENT-BASED MATERIALS: CONSIDERATION OF W/B AND NANOPARTICLE USE
}

\author{
Bo Yeon Lee ${ }^{\mathrm{a} *}$ and Kimberly E. Kurtis ${ }^{\mathrm{b}}$ \\ ${ }^{a}$ Department of Architectural Engineering, The University of Suwon, 17 Wauan-gil, Bongdam-eup, Hwaseong-si, \\ Gyeonggi-do, 18323, South Korea. bylee@ suwon.ac.kr, 82-31-229-8170 \\ ${ }^{\mathrm{b}}$ School of Civil and Environmental Engineering, Georgia Institute of Technology, \\ 790 Atlantic Dr., Atlanta, GA 30332-0355, USA. kimberly.kurtis@ce.gatech.edu, 1-404-385-0825 \\ * Author to whom correspondence should be addressed
}

\begin{abstract}
In this study, the influence of pore structure on the extent of calcium nitrate salt crystallization damage on mortar samples was examined. The pore volume and structure was altered by varying water-to-binder ratio and by adding nanoparticles. The results show that calcium nitrate salt exposure induces cracking in mortar samples and that more damage was observed at higher water-to-binder ratio and higher rate of nanoparticle use. It is proposed that the refined pore structure induced by nanoparticle use can result higher salt crystallizing pressure. Thus, cementitious structures that are expected to be exposed to salt crystallization should be designed to meet strength needs by lowering water-to-binder ratio less than 0.40 . When using nanoparticles of the type examined here, limiting their use to rates of less than $5 \%$ by mass of cement and use of water-to-binder ratio less than 0.40 appears to be prudent.
\end{abstract}

Keywords: microstructure (B), pore size distribution (B), durability (C), transport properties (C), $\operatorname{mortar}(\mathrm{E})$ 


\section{INTRODUCTION}

Porous, brittle materials such as stone, masonry or cement-based materials can be damaged due to pressure induced by salt crystallization occurring in their pores. When the pressures generated exceed the tensile capacity of the material, cracking can result [1]; over time, with cyclic exposure and weathering, progressive damage can compromise the integrity and performance of the affected material. When salt crystallization, in the absence of degrading chemical interaction, is the cause of damage, this phenomenon is called "salt weathering", "salt scaling", "physical salt attack", or "salt crystallization".

Studies examining the salt crystallization damage on porous materials have most often focused on salt crystallization by sodium sulfate, sodium chloride, and sodium carbonate [1-7]. For example, Scherer experimentally studied the stress from crystallization of sodium sulfate salt (thenardite $\left(\mathrm{Na}_{2} \mathrm{SO}_{4}\right)$ and mirabilite $\left(\mathrm{Na}_{2} \mathrm{SO}_{4} \cdot 10 \mathrm{H}_{2} \mathrm{O}\right)$ [1] $)$ in stone. This phenomenon can be explained by precipitation of salt crystals from the liquid in pore structure of a material and also related to phase change from thenardite to mirabilite, which contains 10 molecules of water. Chatterji also experimentally demonstrated that crystal growth pressure exerted by sodium thiosulfate pentahydrate $\left(\mathrm{Na}_{2} \mathrm{~S}_{2} \mathrm{O}_{3} \cdot 5 \mathrm{H}_{2} \mathrm{O}\right)$ could break glass test tubes without confinement [3]. Thaulow has reviewed the mechanisms of surface scaling of concrete due to sodium sulfate salt (thenardite $\left(\mathrm{Na}_{2} \mathrm{SO}_{4}\right)$ and mirabilite $\left.\left(\mathrm{Na}_{2} \mathrm{SO}_{4} \cdot 10 \mathrm{H}_{2} \mathrm{O}\right)\right)$. Comparing three existing proposed damage mechanisms - (1) solid volume change hypothesis, (2) salt hydration pressure hypothesis, and (3) crystallization pressure hypothesis - concluding that damage can only be explained by salt crystallization pressure theory [4]. The damage mechanisms associated with salt 
crystallization in porous materials have been reviewed by Valenza and Scherer [2, 8]. Although not examined as often, other salts including nitrates, oxalates, and acetates, are also known to damage porous materials [9-11]. For example, acetates are known to damage tiles of glazed ceramics by salt crystallization [9], and nitrate $\left(\mathrm{NO}_{3}{ }^{-}\right)$salts, since they derive from fertilizer, are known to damage masonry near agricultural regions [10]. Conservationists have found crystallization of calcium nitrate salts to be particularly damaging to brittle materials such as plasters [12]. In addition to their practical relevance in these applications, study of crystallization of various salts is of interest because of the need to develop accelerated laboratory tests to assess potential for damage in natural and engineered porous materials. Salts which are particularly damaging at faster rates are potentially good candidates for use in accelerated test methods.

Like stone and masonry, cement-based materials are brittle and have a porous microstructure, and have exhibited salt crystallization damage in practice [2, 7]. However, unlike natural materials, the microstructure and hardened properties of cement-based materials, and thus the extent of damage, can be controlled or tailored to enhance durability. Thus, understanding the relationship between the microstructure of cementitious materials and the extent of damage would be the first step to reduce salt crystallization damage on cement-based materials. Such information will allow for improvement of existing building codes and standards, which will allow for effective design of concrete for durability in regions and exposure conditions where salt crystallization is likely.

The objective of this research was to examine specifically the effect of microstructure (e.g., pore size, porosity) of cement-based materials on salt crystallization damage as it relates to damage by 
salt crystallization. Specifically, porosity and pore structure were varied by altering the water-tobinder ratio (w/b) and the dosage of nanoparticles. The w/b influences the volume and size of capillary porosity in cement-based materials [13], and nanoparticles have been shown to refine pore structure since their surfaces serve as nucleation sites during early hydration [14]. Because of the relatively aggressive damage associated with their crystallization, calcium nitrate salts were used to generate damage in cementitious materials; an additional potential advantage is avoidance of leaching of calcium-containing hydration products during soaking in calcium-rich salt solution. Results from the calcium nitrate solution exposures are compared to the more commonly examined sodium sulfate salts. Here, two different calcium nitrate solution concentrations (15\% and 30\%) were utilized and compared with $15 \%$ sodium sulfate solution as well as samples exposed to deionized water, as a control.

\section{THEORETICAL BACKGROUND}

Over recent decades, several mechanisms have been proposed to explain the phenomenon of damage due to crystallization in porous brittle materials. The most widely accepted is the theory of salt crystallization by supersaturation proposed by Scherer [1]. It has been extended to assess damage to porous, brittle materials by ice formation, as well as various forms of salt crystallization (e.g., sulfate attack, delayed ettringite formation). The theory considers the pressure exerted by a crystallizing salt and examines conditions which can induce cracking of porous materials such as cement and concrete. The extent of damage depends on the supersaturation of the salt, the size of the pores, and a disjoining pressure between the growing crystal and pore wall [1]. A solute in a supersaturated solution has higher potential energy than in 
a corresponding saturated solution, which performs work against an external confining surface when the solute crystallizes out of solution [3]. The supersaturation can be achieved by several means. When there is a quick drop in temperature without nucleation occurring, the solution becomes supersaturated. Also, as is more often the case, the evaporation of liquid can lead to supersaturation near the drying front. In this paper, only the case of capillary rise and evaporation leading to supersaturation and eventually salt crystallization will be examined and discussed.

When a porous material, such as cement or concrete, is in contact with a continuous supply of salt solution, the solution is drawn into the pores of a material by capillary suction. The flux, as a result of capillary pressure, can be written as Equation (3), which is derived from Darcy's law.

$$
\mathrm{Jc}=\phi \overline{\mathrm{A}} \frac{\mathrm{dh}}{\mathrm{dt}}=\frac{\mathrm{k}}{\eta} \frac{\left(-\mathrm{p}_{\mathrm{c}}-\rho_{\mathrm{L}} \mathrm{gh}\right)}{\mathrm{h}}
$$

Here, $\mathrm{J}_{\mathrm{c}}$ is the flux from the capillary rise, $\phi$ is the porosity of a material, $\overline{\mathrm{A}}$ is the area of the surface in contact with the ground, $k$ is the permeability, $\eta$ is the viscosity, $p_{c}$ is capillary pressure, $\rho_{\mathrm{L}}$ is the density of the liquid, $\mathrm{g}$ is the gravitational acceleration, and $\mathrm{h}$ is the height to which the liquid has risen. Capillary pressure $\mathrm{p}_{\mathrm{c}}(<0)$ is proportional to the interfacial tension, $\gamma$, inversely proportional to the effective radius, $r$, of the pore, and depends on the wetting angle, $\theta$, of the liquid on the surface of the capillary, as shown in Equation (4).

$$
p_{c}=\frac{2 \gamma \cos \theta}{\mathrm{r}}
$$


Note here that the flux, or rate of rise, decreases as $\mathrm{h}$ increases. On the other hand, the rate of evaporation from the surface of a material, $\mathrm{J}_{\mathrm{E}}$, is constant at any height. This makes an equilibrium height, $\mathrm{h}_{\mathrm{s}}$, where the rate of capillary rise and drying are equal. As the water evaporates from the porous material, the concentration of salt increases near the surface of a material. Near the region of contact with the solution, the concentration gradient is not large enough to lead to supersaturation because the salt diffuses back towards the source. This causes the lower part of a structure to remain relatively wet under these exposure conditions. Above this region, salt concentration at the drying surface increases, ultimately reaching supersaturation. At this level, salt precipitates out on the surface of a material, which is called "efflorescence". Above the equilibrium height, $\mathrm{h}_{\mathrm{s}}$, the rate of evaporation exceeds the rate of capillary rise, which results in salt crystallization within the pores of the material. It is in this "subflorescence region", where damage may occur when the crystallization pressure exceeds tensile strength of a material. The damage tends to produce a conical shape for a prismatic sample. A schematic of capillary rise and evaporation is shown in Figure 1 (reproduced based upon Scherer [1]). In this study, experimental conditions were designed to generate subflorescence within the sample. 


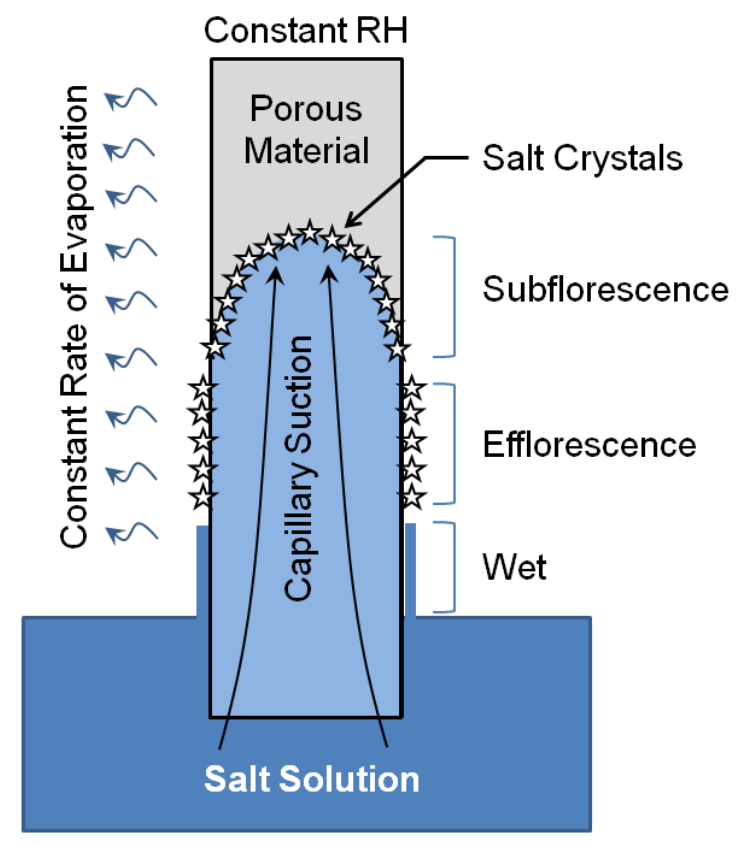

Figure $1-$ Schematic of capillary rise and evaporation.

\section{MATERIALS AND EXPERIMENTAL PROCEDURE}

\section{$\underline{\text { 3.1 Materials }}$}

Mortar bars were produced from an ASTM C 150 Type I portland cement and standard 20-30 Ottawa sand that conforms to ASTM C778. In order to physically modify the pore structure of cement-based materials, nanoparticles of titanium dioxide $\left(\mathrm{TiO}_{2}\right)$ were mixed in the mortar bar samples. In this study, the $\mathrm{TiO}_{2}$ powder used was $\mathrm{P} 25$ (Aeroxide $\mathrm{TiO}_{2} \mathrm{P} 25$, Evonik Industries). This type of $\mathrm{TiO}_{2}$ is sold in the form of agglomerates and is known to be chemically inert (i.e., does not directly participate in cement hydration, latent hydraulic or pozzolanic reactions). Particle size distribution of the $\mathrm{TiO}_{2}$ agglomerates was measured in water (Zetasizer Nano, Malvern Instruments, UK), as shown in Figure 2. The average crystal size is $21 \mathrm{~nm}$, the surface area is $50 \pm 15 \mathrm{~m}^{2} / \mathrm{g}$, and the sample purity is $99.5 \%$, as stated by the manufacturer. 
In this research, $15 \%$ and $30 \%$ calcium nitrate $\left(\mathrm{Ca}\left(\mathrm{NO}_{3}\right)_{2} \cdot 4 \mathrm{H}_{2} \mathrm{O}, 99.0 \%\right.$ purity) salt solution and $15 \%$ sodium sulfate $\left(\mathrm{Na}_{2} \mathrm{SO}_{4} \cdot 10 \mathrm{H}_{2} \mathrm{O}, 99.0 \%\right.$ purity) solution were used. Exposure to deionized water with $18.2 \mathrm{M} \Omega \cdot \mathrm{cm}$ resistivity was used a control. All solutions were produced with this deionized water source.

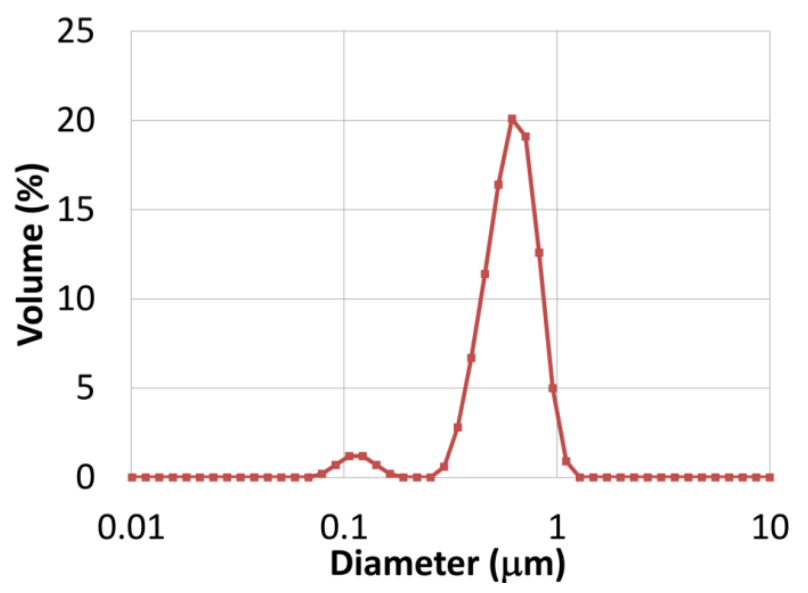

Figure 2 - Particle size distribution of $\mathrm{TiO}_{2}$ powder.

\subsection{Sample Preparation}

In this study, the effect of pore structure on salt crystallization was investigated by controlling two variables; the water to-binder ratio (w/b) and the amount of $\mathrm{TiO}_{2}$ use. Mortar samples were prepared with w/b of $0.40,0.50$, and 0.60 , while a constant amount of $\mathrm{TiO}_{2}$ was used at $5 \%$ cement replacement by mass. Here, $\mathrm{TiO}_{2}$ was considered in the binder mass. Likewise, in a second series of samples, w/b was kept constant at 0.50 and mortar samples were prepared with $0 \%, 5 \%$, and $10 \%$ of $\mathrm{TiO}_{2}$ replacement by mass of cement, where the $\mathrm{TiO}_{2}$ powder was considered as binder. Mortar bars were made based on a cement-aggregate mass ratio of 1:2.23 for all of the samples. 
When mixing the mortar, the $\mathrm{TiO}_{2}$ powder was first mixed with deionized water for 1 minute in a planetary mixer to better disperse the particles. The remainder of the mortar mixing followed ASTM C305 procedures.

Mortar bars were cast in $2.54 \times 2.54 \times 25.4 \mathrm{~cm}(1 \times 1 \times 10$ inch) brass molds. Prior to casting, the molds were coated with thin layer form release agent. The samples were cured in $100 \%$ relative humidity $(\mathrm{RH})$ for 24 hours at normal room temperature $\left(23 \pm 2^{\circ} \mathrm{C}\right)$, and then demolded and continued to be cured in limewater until 7 days of age at room temperature. The samples were removed from limewater at 7 days and cut into approximately $9 \mathrm{~cm}$ bars with a wet saw. Both ends of mortar bars were also cut so that all specimen ends have similar ability to absorb the salt solution or water. The samples were then stored at room temperature and at $\mathrm{RH}=50 \pm 5 \%$ for 3 days before the onset of the salt crystallization experiment. It is assumed that the samples have reached equilibrium moisture content at the time of the onset of the experiment. Note that the samples were not oven dried prior to the experiment in order to avoid possible alterations to microstructure.

\section{$\underline{\text { 3.3 Test Chamber }}$}

The test method for salt crystallization was based upon that described for stone by Scherer [1]. That test was further modified to be applied to cement-based materials and for use on relatively smaller samples. The test was comprised of mortar bar samples suspended from the top of a glass-sided test chamber and partially immersed in test salt solution at the bottom while the environmental RH is controlled. Here, the test salt solution is absorbed from the bottom part of 
the samples, drawn upward by capillary suction, and then evaporated on the surface of the samples, as demonstrated in Figure 1. Each test solution was prepared in an enclosed container with an opening where the sample was inserted. To compensate for the loss of salt solution due to suction and evaporation, a "back up" salt solution was connected to the reservoir such that the level of test solution is kept constant. The sample should fit through the opening tightly in order to minimize the possibility for moisture transport between the test solution container and the chamber. Visually, moisture migration along the sample surface (evident by darkening) was not observed for any of the samples.

The RH in the chamber was maintained so that the evaporative flux was controlled at all times. The $\mathrm{RH}$ was maintained at $35 \pm 3 \%$ at room temperature $\left(23 \pm 2^{\circ} \mathrm{C}\right)$ throughout the experiment using saturated calcium chloride $\left(\mathrm{CaCl}_{2}\right)$ solution [15] which was contained below test solution containers. To keep the $\mathrm{CaCl}_{2}$ solution saturated at all times regardless of added moisture from the evaporation of the samples, the $\mathrm{CaCl}_{2}$ reservoir was maintained frequently. The solution concentration was monitored and a magnetic stirrer was used throughout the experiment to facilitate mixing. A diagram of the test setup is presented in Figure 3, and picture of the actual experimental setup is presented in Figure 4. 


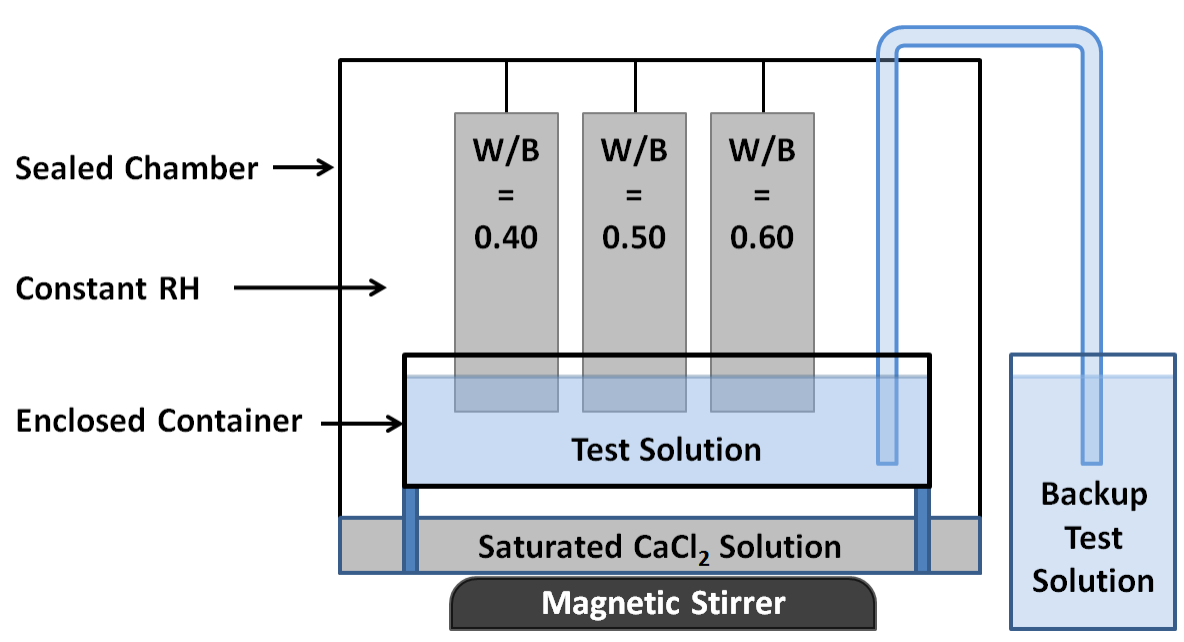

Figure 3 - Schematic diagram of the experimental setup.

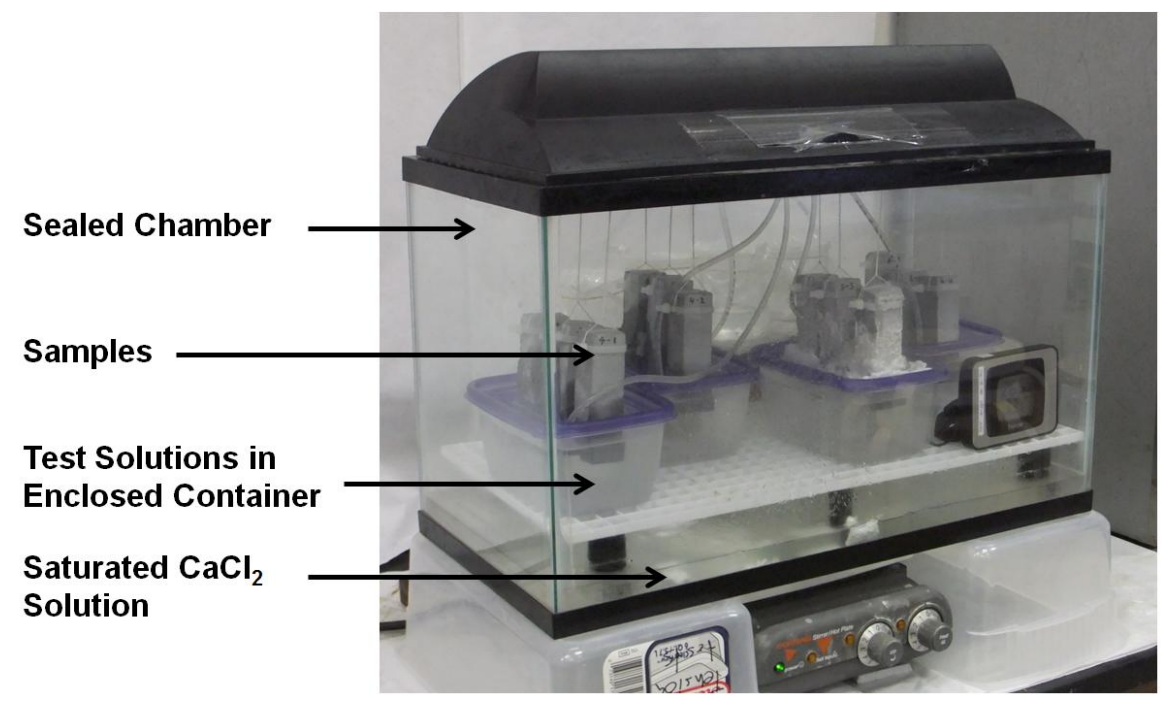

Figure 4 - Picture of the experimental setup.

\subsection{Experimental Rationale}

The first part of the experiment examines the effect of water-to-binder ratio $(w / b)$ and different salt solutions. The varying w/b is expected to affect pore structure and strength. As described above, mortar bars were cast with w/b of $0.40,0.50$, and 0.60 , all with $5 \% \mathrm{TiO}_{2}$ replacement of cement. These mortar bars were tested in $15 \%$ and $30 \% \mathrm{Ca}\left(\mathrm{NO}_{3}\right)_{2}$ solutions by mass, $15 \%$ 
$\mathrm{Na}_{2} \mathrm{SO}_{4}$ solution by mass, and deionized water as a control. The samples were partially immersed for 65 days.

The second series of experiments examines the effect of different amounts of nano- $\mathrm{TiO}_{2}$ use. Lee et al. reported that the nanoparticles of $\mathrm{TiO}_{2}$ promote cement hydration due to nucleation effect [16]. This alters the microstructure of cementitious materials (as will be presented herein), which could affect transport properties and thus long-term durability as well. Here, as noted previously, mortar bar samples with $0 \%, 5 \%$, and $10 \%$ of $\mathrm{TiO}_{2}$ replacement by mass of cement were used while $\mathrm{w} / \mathrm{b}$ was constant at 0.50 . The samples were tested in $15 \% \mathrm{Ca}\left(\mathrm{NO}_{3}\right)_{2}$ solution for 92 days. The experimental plan is summarized in Table 1.

Table 1. Salt crystallization experimental plan. "O" indicates conditions for which samples were produced.

\begin{tabular}{|c|c|c|c|c|c|c|c|}
\hline & \multicolumn{4}{|c|}{ Part 1 } & \multicolumn{3}{c|}{ Part 2 } \\
\hline & \multicolumn{3}{|c|}{$5 \% \mathrm{TiO}_{2}$ sample } & $\mathrm{TiO}_{2}$ & $5 \% \mathrm{TiO}_{2}$ & $10 \% \mathrm{TiO}_{2}$ \\
\hline & $\begin{array}{c}\mathrm{Ca}\left(\mathrm{NO}_{3}\right)_{2} \\
15 \%\end{array}$ & $\begin{array}{c}\mathrm{Ca}\left(\mathrm{NO}_{3}\right)_{2} \\
30 \%\end{array}$ & $\begin{array}{c}\mathrm{Na}_{2} \mathrm{SO}_{4} \\
15 \%\end{array}$ & $\begin{array}{c}\text { Deionized } \\
\text { water }\end{array}$ & \multicolumn{3}{c|}{$\mathrm{Ca}\left(\mathrm{NO}_{3}\right)_{2} 15 \%$} \\
\hline w/b=0.40 & $\mathrm{O}$ & $\mathrm{O}$ & $\mathrm{O}$ & $\mathrm{O}$ & & & \\
\hline w/b=0.50 & $\mathrm{O}$ & $\mathrm{O}$ & $\mathrm{O}$ & $\mathrm{O}$ & $\mathrm{O}$ & $\mathrm{O}$ & $\mathrm{O}$ \\
\hline w/b=0.60 & $\mathrm{O}$ & $\mathrm{O}$ & $\mathrm{O}$ & $\mathrm{O}$ & & & \\
\hline
\end{tabular}




\section{RESULTS AND DISCUSSION}

As previously stated, the pore structure of cementitious materials was modified either by varying water-to-binder ratio or by using nanoparticles of chemically inert $\mathrm{TiO}_{2}$. The results of the two series of experiments are presented separately.

\section{$\underline{4.1 \text { Effect of Varying Water-to-Binder Ratio }}$}

The mortar bar samples at $\mathrm{w} / \mathrm{b}=0.40,0.50$, and 0.60 were tested in $15 \% \mathrm{Ca}\left(\mathrm{NO}_{3}\right)_{2}$ solution, $30 \%$ $\mathrm{Ca}\left(\mathrm{NO}_{3}\right)_{2}$ solution, $15 \% \mathrm{Na}_{2} \mathrm{SO}_{4}$ solution, and deionized water for 65 days. Samples were visually inspected with the unaided eye and with a stereomicroscope (Leica MZ6) at 12.6-20X magnification. Visual observations made at the end of the exposure period are presented in Figures $5,6,7,8$ for the $15 \% \mathrm{Ca}\left(\mathrm{NO}_{3}\right)_{2}$ solution, $30 \% \mathrm{Ca}\left(\mathrm{NO}_{3}\right)_{2}$ solution, $15 \% \mathrm{Na}_{2} \mathrm{SO}_{4}$ solution, and deionized water, respectively. In addition, mass of the mortar bars were measured for all the samples at 7 days and 65 days after the onset of the salt crystallization experiment. Percent mass change was calculated relative to the initial mass of each mortar bar. The results are presented in Table 2 .

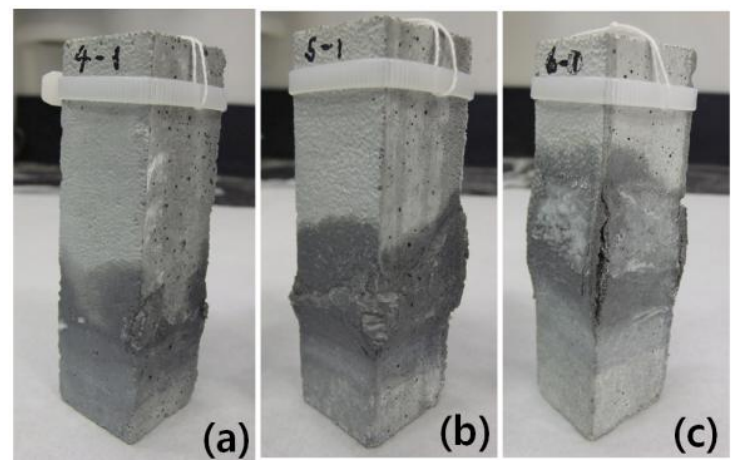

Figure 5 - Samples tested in $15 \% \mathrm{Ca}\left(\mathrm{NO}_{3}\right)_{2}$ solution

(a) $w / b=0.40,(b) w / b=0.50$, and (c) $w / b=0.60$ after 65 days of exposure. 


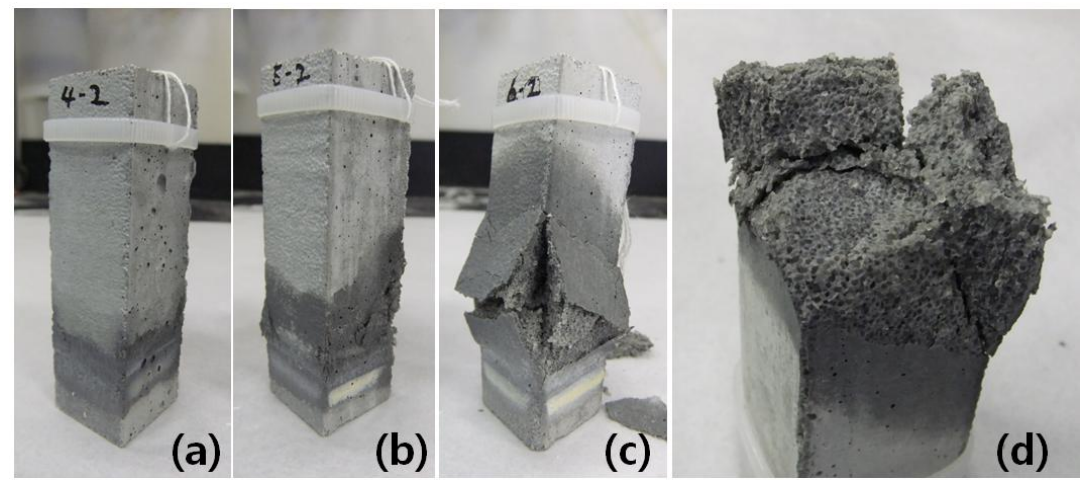

Figure 6 - Samples tested in $30 \% \mathrm{Ca}\left(\mathrm{NO}_{3}\right)_{2}$ solution

(a) $w / b=0.40$, (b) $w / b=0.50$, (c) $w / b=0.60$, and (d) fractured section detail of $w / b=0.60$ sample after 65 days of exposure.
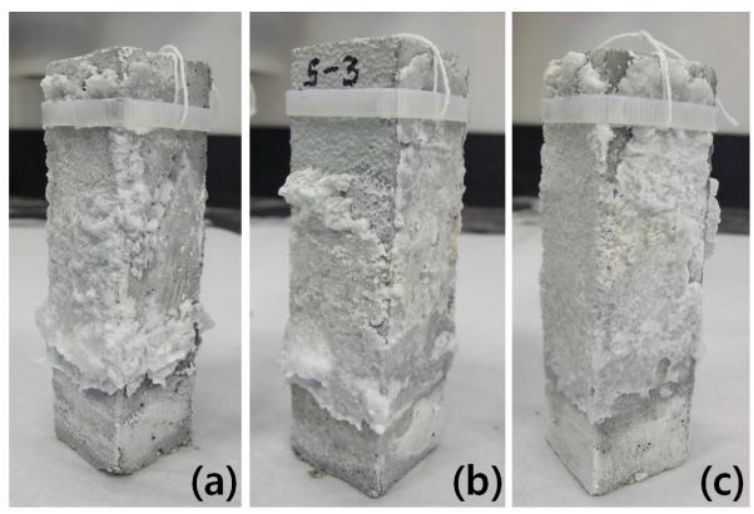

Figure 7 - Samples tested in $15 \% \mathrm{Na}_{2} \mathrm{SO}_{4}$ solution

(a) $w / b=0.40$, (b) $w / b=0.50$, and (c) $w / b=0.60$ after 65 days of exposure. 

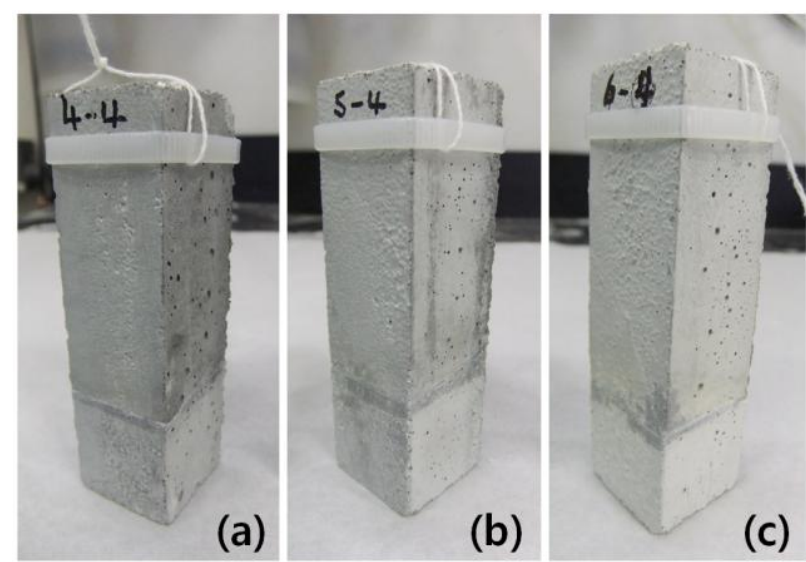

Figure 8 - Samples tested in deionized water

(a) $w / b=0.40,(b) w / b=0.50$, and (c) $w / b=0.60$ after 65 days of exposure.

Table 2. Percent mass change of mortar samples relative to the initial mass after 7 days and 65 days of exposure

\begin{tabular}{|c|c|c|c|c|c|c|c|c|}
\hline & \multicolumn{2}{|c|}{$\mathbf{C a}\left(\mathbf{N O}_{\mathbf{3}}\right)_{\mathbf{2}} \mathbf{1 5 \%}$} & \multicolumn{2}{c|}{$\mathbf{C a}\left(\mathbf{N O}_{\mathbf{3}}\right)_{\mathbf{2}} \mathbf{3 0 \%}$} & \multicolumn{2}{c|}{$\mathbf{N a}_{\mathbf{2}} \mathbf{S O}_{\mathbf{4}} \mathbf{1 5 \%}$} & \multicolumn{2}{c|}{ DI water } \\
\hline & $\mathbf{7}$ days & $\mathbf{6 5}$ days & $\mathbf{7}$ days & $\mathbf{6 5}$ days & $\mathbf{7}$ days & $\mathbf{6 5}$ days & $\mathbf{7}$ days & $\mathbf{6 5}$ days \\
\hline $\mathbf{w} / \mathbf{b}=\mathbf{0 . 4 0}$ & $0.11 \%$ & $-0.22 \%$ & $0.36 \%$ & $-0.48 \%$ & $1.23 \%$ & $5.60 \%$ & $0.36 \%$ & $-0.55 \%$ \\
\hline $\mathbf{w} / \mathbf{b}=\mathbf{0 . 5 0}$ & $0.28 \%$ & $3.17 \%$ & $0.41 \%$ & $1.51 \%$ & $1.23 \%$ & $6.67 \%$ & $0.67 \%$ & $-0.52 \%$ \\
\hline $\mathbf{w} / \mathbf{b}=\mathbf{0 . 6 0}$ & $1.70 \%$ & $7.08 \%$ & $2.03 \%$ & $12.20 \%$ & $2.97 \%$ & $11.89 \%$ & $1.41 \%$ & $-0.37 \%$ \\
\hline
\end{tabular}

The exposure solution had a strong influence on the forms of damage observed. Overall, the samples tested in $\mathrm{Ca}\left(\mathrm{NO}_{3}\right)_{2}$ solution experienced cracking and spalling, meaning that $\mathrm{Ca}\left(\mathrm{NO}_{3}\right)_{2}$ salt could induce substantial expansion and cracking on cement-based materials that could lead to complete destruction, as shown in Figures 5 and 6. The samples in $\mathrm{Na}_{2} \mathrm{SO}_{4}$ solution showed heavy efflorescence on the outside of the samples, covering each sample to its top, but no damage was observed on the sample surface. The control samples in DI water appeared to be 
sound, showing no damage other than some differences in surface color above and below the water line after 65 days of exposure.

Comparing Figures 6 (a), (b), and (c), the effect of w/b on calcium nitrate salt crystallization damage can be observed. Among the three water-to-binder ratios examined, the mortars prepared at $w / b=0.60$ exhibited the most severe cracking, which was characterized by spalling of the outer layer of mortar samples (Figure 6(c)). By the end of the exposure period, the sample was completely broken in half, indicating that salt crystallization damage affected the entire crosssection of the sample. Although not as extreme as in the $30 \% \mathrm{Ca}\left(\mathrm{NO}_{3}\right)_{2}$ case shown in Figure 6 , a similar trend was observed in the $15 \% \mathrm{Ca}\left(\mathrm{NO}_{3}\right)_{2}$ case in Figures 5: the higher water-to-binder mortar exhibited the most severe damage. From both cases, major cracking initiated from each corner, where the drying rate is relatively faster due to two dimensional drying, and propagated inwards forming a conical shape towards the inner part of the prism (Figure 6 (d)). Compared to the $w / b=0.60$ mortar, the $w / b=0.50$ mortar was damaged to a lesser degree in both of the $\mathrm{Ca}\left(\mathrm{NO}_{3}\right)_{2}$ solutions. The $\mathrm{w} / \mathrm{b}=0.40$ mortar experienced only subtle damage on the corner of the samples in both solutions, as observed by visual inspection. It can be concluded that the higher w/b adversely affects the soundness of mortar by salt crystallization.

The different behavior observed for the different w/b samples is believed to be related to the following concepts. First, it is likely that the lower w/b results in a more discontinuous capillary pore structure that interrupts the capillary rise of the dissolved salts, thus limiting internal salt crystallization. From Table 2, a greater percent mass change was observed for the higher w/b samples in all of the solutions tested, even at relatively early exposure time of 7 days. At this 
relatively early age, it is assumed that salt precipitation is negligible. Thus, the increase in mass is related to the capillary flux of salt solution through the pore structure in the samples. As shown in Equation 3, capillary flux increases proportionally as porosity and permeability increase. Therefore, the increased porosity and permeability, and thus the increased pore connectivity, with higher $w / b$ are related to increased rate of salt solution transport. It is believed that the effect of increases in salt solution uptake overcomes the decrease in capillary pressure in larger pores produced at higher w/b (Equation 4), which ultimately facilitates salt crystallization damage. This is visually confirmed comparing either Figures 5 (a), (b), and (c) or Figures 6 (a), (b), and (c). The location of the drying front, characterized by darker color within each sample, was observed at greater height for the higher w/b samples, confirming the transport behavior mentioned above. The mass increase was also more pronounced at longer exposure time with increasing $\mathrm{w} / \mathrm{b}$. This is expected as more salts are able to crystallize and accumulate in or on the more porous samples with time. The $w / b=0.60$ sample showed $7.08 \%$ mass increase at 65 days for the $15 \% \mathrm{Ca}\left(\mathrm{NO}_{3}\right)_{2}$ case, and $12.20 \%$ for the $30 \% \mathrm{Ca}\left(\mathrm{NO}_{3}\right)_{2}$ case.

Second, decreased mortar strength with increased water-to-binder ratio directly affects resistance to salt crystallization cracking. It is well-known that increased water-to-binder ratio leads to higher porosity, which decreases bulk strength of a material. When the salt crystallization pressure exceeds tensile strength of a material, cracking occurs. Based on a general understanding that tensile strength of a material has a direct relationship with compressive strength, Valenza noted that as the compressive strength approaches a value of $40 \mathrm{MPa}$, the salt scaling resistance of the material should be satisfactory [2]. This suggests that salt crystallization damage can be mitigated by lowering $\mathrm{w} / \mathrm{b}$, as $\mathrm{w} / \mathrm{b}$ is conventionally inversely proportional to 
compressive strength. In the authors' prior work [17], compressive strength of cement paste samples containing the same type of nanoparticle was examined at same percentage replacement and at same w/b. As expected, a higher w/b resulted lower compressive strength, with strengths near $40 \mathrm{MPa}$ in the $\mathrm{w} / \mathrm{b}=0.60$ case. A similar trend is expected in this study for the mortar samples but with lower strength, because the strength of mortar is generally lower than cement paste [18]. As a result, it is likely that the salt scaling resistance of the $w / b=0.60$ mortar bar was not satisfactory, which had led to disruptive cracking.

These results suggest that the benefit derived from discontinuous capillary pore structure and increasing strength with lower w/b outweighs the potential detriment of increased crystallization pressure due to smaller pore sizes at lower water-to-binder ratio, within the range of w/b examined. Thus, as expected, the higher water-to-binder ratio samples are more susceptible to $\mathrm{Ca}\left(\mathrm{NO}_{3}\right)_{2}$ salt solution ingress and to salt-induced cracking, and that an extended exposure time is likely to increase the amount of damage.

It should also be noted that the location where cracking occurs varies with w/b. As the w/b increases, the cracks form at greater heights above the solution surface (Figures 5 and 6). This is again believed to be related to the pore structure and transport behavior in the samples. The drying front developed at greater height for the higher w/b is linked to the location of subflorescence. Thus, higher w/b not only affects strength, but also the location where salt crystallization damage might occur. 
Comparing samples in $15 \%$ and $30 \% \mathrm{Ca}\left(\mathrm{NO}_{3}\right)_{2}$ solutions, samples subjected to the higher concentration solution experienced more severe damage, as expected. This indicates that higher concentration of salt solution produced more salt crystals, resulting in higher level of salt crystallization pressure, leading to more severe damage. This can be attributed to two causes. Higher concentration salt solution, when dried, produces a greater amount of salt crystals than lower concentration when other variables are constant. Also, the amount of salt solution that is drawn up is greater in higher concentration salt solution, as shown in Table 2. Comparing percent mass change at 7 days for two groups, the percent mass increase is greater for the $30 \%$ $\mathrm{Ca}\left(\mathrm{NO}_{3}\right)_{2}$ case than for the $15 \% \mathrm{Ca}\left(\mathrm{NO}_{3}\right)_{2}$ case for all of the $\mathrm{w} / \mathrm{b}$ examined. The difference in the flux between 15 and $30 \% \mathrm{Ca}\left(\mathrm{NO}_{3}\right)_{2}$ solutions is related to solution density, viscosity, and interfacial tension and the influence of these on capillary pressure, as stated by Equation 3. With exposure time, as more salts are likely to crystallize and accumulate in or on the samples, the mass increase is greater. Specifically, for example, a $12.20 \%$ mass increase was observed for the $\mathrm{w} / \mathrm{b}=0.60$ mortar subjected to $30 \% \mathrm{Ca}\left(\mathrm{NO}_{3}\right)_{2}$ solution, which is $72 \%$ greater than the $15 \%$ $\mathrm{Ca}\left(\mathrm{NO}_{3}\right)_{2}$ case at the same exposure time. It can be noted that the $\mathrm{w} / \mathrm{b}=0.40$ samples in both $\mathrm{Ca}\left(\mathrm{NO}_{3}\right)_{2}$ solutions and the samples exposed to the deionized water experienced negative mass change at 65 days. This means that the mass prior to the exposure is greater than the mass after 65 days of partial immersion in test solutions. This indicates that not only were there enough (or no) salts to be accumulated, but also drying was induced by the relatively low RH such that the mass of evaporated water from the surface of a sample was greater than the mass of the salt solution that had been absorbed. This is possible because the samples were not oven dried prior to the exposure to the salt solution, to avoid the introduction of cracks which may influence 
damage propagation. Also, there is a potential for leaching of ions into the solutions. Any effect, however, appears to be small, given the magnitude of the negative mass change.

The samples tested in $\mathrm{Na}_{2} \mathrm{SO}_{4}$ solution developed heavy efflorescence within several days after the start of the experiment, with white deposits covering the entire air-exposed sample surfaces including the top, at all w/b. The thickness of the deposit continued to increase with time, reaching $\sim 2-5 \mathrm{~mm}$ at some areas, and no difference was observed with varying w/b. Cracking or spalling was not observed on all of the sample surfaces. Typically, efflorescence negatively impacts the aesthetics of a structure, but does not affect its soundness. While the more damaging subflorescence occurs at above the efflorescence, the mortar bars were not of an ample height to support that mode of deposition. If the mortar bars were long enough, the flux will decrease with increasing height (Equation 3) and eventually reach equilibrium at height, $\mathrm{h}_{\mathrm{s}}$, where subflorescence is expected to develop. It is believed that the sample with higher $w / b$ is expected to have more salt crystallization damage and at higher height, as demonstrated in $\mathrm{Ca}\left(\mathrm{NO}_{3}\right)_{2}$ cases. The difference in the height of the drying front, or in the flux between $\mathrm{Ca}\left(\mathrm{NO}_{3}\right)_{2}$ and $\mathrm{Na}_{2} \mathrm{SO}_{4}$ solutions, seem to be, again, related to density, viscosity, and interfacial tension of the solution and the influence of these on capillary pressure (Equation 3).

The $\mathrm{Na}_{2} \mathrm{SO}_{4}$ salt precipitated on the sample surface was scraped off and examined by $\mathrm{x}$-ray diffraction analysis, under $\mathrm{Cu}-\mathrm{K} \alpha$ radiation. It was confirmed to be pure thenardite, the anhydrous form of $\mathrm{Na}_{2} \mathrm{SO}_{4}$ (Figure 9). Considering that the salt used for making the solution is mirabilite $\left(\mathrm{Na}_{2} \mathrm{SO}_{4} \cdot 10 \mathrm{H}_{2} \mathrm{O}\right)$, the humidity condition in this experiment is low enough that anhydrous thenardite salt precipitates, since the phase diagram for sodium sulfate indicates that 
thenardite transforms to mirabilite at $\mathrm{RH}=\sim 78 \%$ at $25^{\circ} \mathrm{C}$ [19]. Although the damage mechanism due to sodium sulfate remains a subject of debate, it is believed that thenardite dissolution generates high supersaturation with respect to mirabilite, and that crystallization stress of mirabilite growth induces damage [19]. In these experimental conditions, the mirabilite solution dried out into anhydrous thenardite, producing conditions which are the opposite of those associated with generation of disruptive crystallization damage. This suggests that the mortars in sodium sulfate solution in this experiment are not conditioned under the worst-case scenario for damage. However, supersaturation is still expected during drying, such as calcium nitrate solution cases, leading to salt crystallization stress. Overall, however, future studies should be designed to ensure generation of the more disruptive hydrous mirabilite salt when examining sodium sulfate salt crystallization damage.

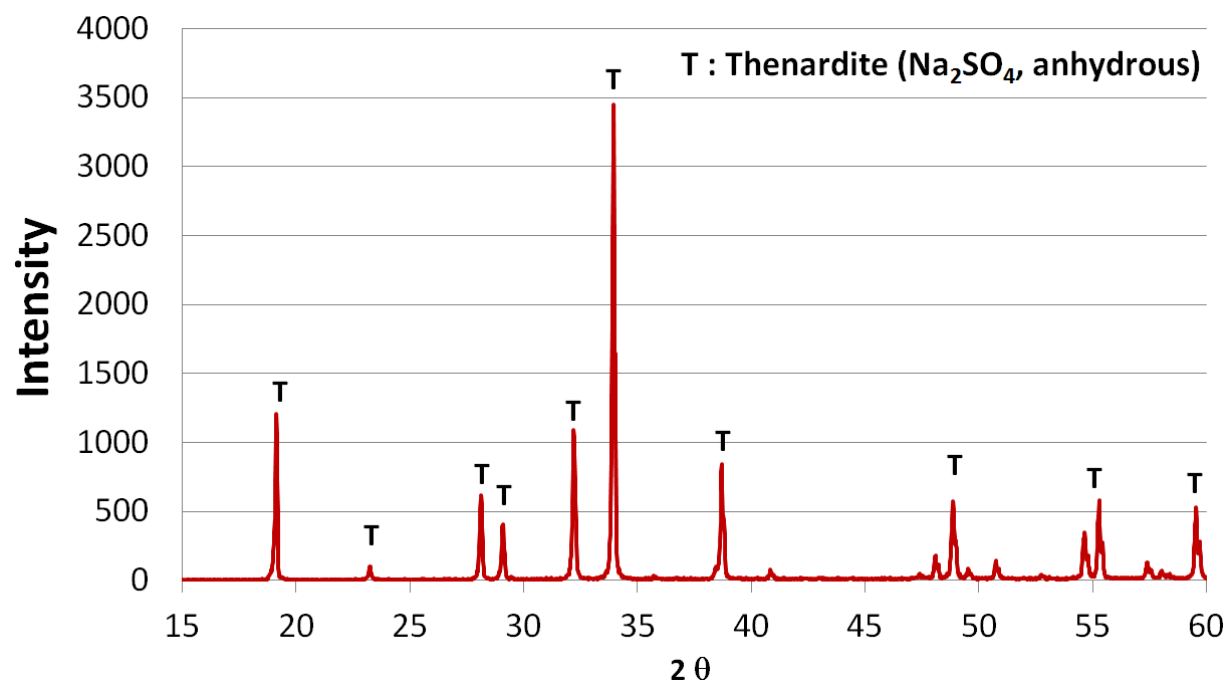

Figure $9-X$-ray diffraction pattern of salt outside of $w / b=0.60$ sample immersed in $15 \%$ $\mathrm{Na}_{2} \mathrm{SO}_{4}$ solution. "T" designates Thenardite, anhydrous form of $\mathrm{Na}_{2} \mathrm{SO}_{4}$. 
In addition to visual inspection, optical microscopy was performed on samples tested in $\mathrm{Ca}\left(\mathrm{NO}_{3}\right)_{2}$ solution $(15 \%$ and $30 \%)$ after 65 days of exposure. Fracture surfaces were examined, without polishing or cutting to avoid altering the structure. In all of the samples, needle-like structures along with glassy, amorphous-appearing deposits were observed within cracks. It appears that the needle-like crystallized salts were deposited inside the cracks, but on the exterior surfaces the less structurally organized deposits are more characteristic. It is believed that the salts exerted crystallizing pressures, which opened the cracks. After exerting crystallizing pressure, the needle-like crystallized salts might have taken in water from the cement paste or could have absorbed moisture from the atmosphere due to highly hygroscopic nature of the salt, changing it into glassy, amorphous products that covered the inside of cracks on cement pastes and sand particles.

To better understand the interactions between the calcium nitrate solution and the cement paste, X-ray diffraction (XRD) was performed on a "deteriorated sample" to identify the composition of crystalline precipitates observed. Analysis was performed on powdered samples obtained from the $\mathrm{w} / \mathrm{b}=0.60$ sample after 65 days in $30 \% \mathrm{Ca}\left(\mathrm{NO}_{3}\right)_{2}$ solution, as well as a companion sample of the same composition but not exposed to salt solution in comparison, noted as "sound sample". This salt-exposed sample was chosen because it experienced the most damage and thus was anticipated to have the most amount of salt formed. The damaged part was collected and crushed. During this step, sand particles were removed using No. 50 sieve $(0.297 \mathrm{~mm}$ opening $)$ to minimize the intensity of the quartz peaks in the diffraction pattern. Using mortar and pestle, the powders were then ground and examined under $\mathrm{Cu}-\mathrm{K} \alpha$ radiation. The powders were prepared and examined using the same method for the sound sample. As shown in Figure 10, calcium 
nitrate hydrate was identified in two forms $-\mathrm{Ca}\left(\mathrm{NO}_{3}\right)_{2} \cdot 2 \mathrm{H}_{2} \mathrm{O}$ and $\mathrm{Ca}\left(\mathrm{NO}_{3}\right)_{2} \cdot 4 \mathrm{H}_{2} \mathrm{O}$ - in case of the deteriorated sample. In addition, another nitrate compound, $\mathrm{Ca}(\mathrm{OH}) \mathrm{NO}_{3}\left(\mathrm{H}_{2} \mathrm{O}\right)$ was also found, suggesting chemical reactions have occurred between the salt from the solution with the cementitious materials. It is notable that calcium hydroxide $\left(\mathrm{Ca}(\mathrm{OH})_{2}\right)$, a major crystalline phase in cementitious materials, was not found in the deteriorated portion of the sample, compared with the sound sample. This suggests that the calcium hydroxide could potentially react with the calcium nitrate salt, leading to the formation $\mathrm{Ca}(\mathrm{OH}) \mathrm{NO}_{3}\left(\mathrm{H}_{2} \mathrm{O}\right)$.

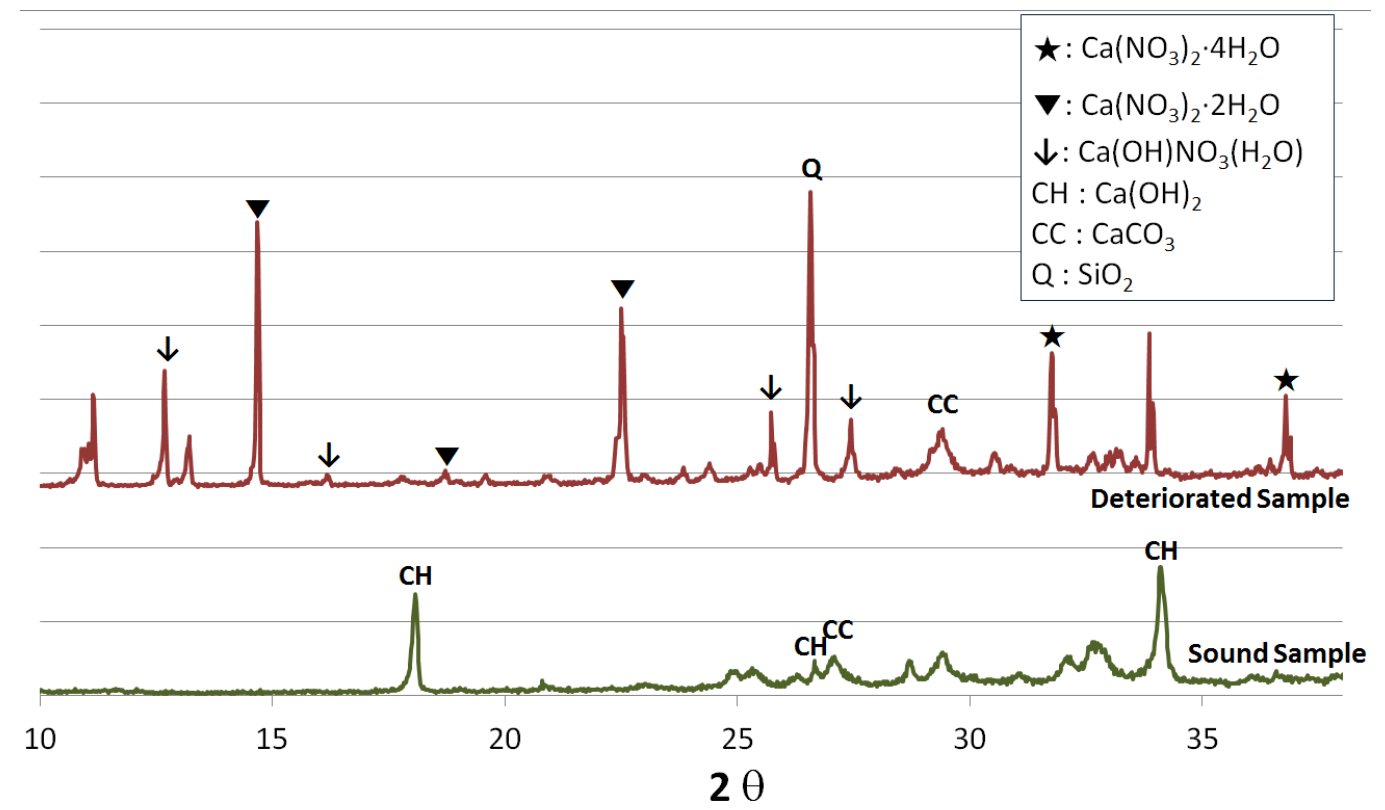

Figure $10-\mathrm{X}$-ray diffraction pattern of $\mathrm{w} / \mathrm{b}=0.60$ sample. The top pattern represents the deteriorated sample tested in $30 \% \mathrm{Ca}\left(\mathrm{NO}_{3}\right)_{2}$ solution, and the bottom pattern represents sound (unaffected) sample. 


\subsection{Effect of Different Amounts of Nanomodification of Porosity}

A similar experiment was performed with samples prepared at a common w/b but with different amounts of $\mathrm{TiO}_{2}$ nanoparticles in order to examine the effect of pore size refinement. The mean size of each $\mathrm{TiO}_{2}$ agglomerate is less than $1 \mu \mathrm{m}$ in diameter (Figure 2), which is more than 10 times smaller than the size of a typical Type I portland cement particle. The use of these nanoparticles would affect pore refinement and the transport of salt solutions. Mortar bar samples $(\mathrm{w} / \mathrm{b}=0.50)$ containing $0 \%, 5 \%$, and $10 \%$ of $\mathrm{TiO}_{2}$ nanoparticles were tested in $15 \%$ $\mathrm{Ca}\left(\mathrm{NO}_{3}\right)_{2}$ solution for 92 days. The longer exposure period was necessitated by the reduction in the rate of transport in these samples relative to the prior series. Note here, that the $\mathrm{TiO}_{2}$ nanoparticles were used as replacement for cement and not as addition. This was to ensure that the strength of samples is relatively constant among the samples. From the authors' prior study [17], it was found that compressive strength of cement paste samples did not vary significantly between $0 \%, 5 \%$, and $10 \%$ cement replacement by same type of nanoparticles at same w/b. Thus, in this part of the study, the effect of strength on salt crystallization damage was considered negligible and only the microstructural effects due to nanoparticles use and pore size refinement was examined.

Samples were inspected visually and by optical microscopy. The visual inspection results are presented in Figure 11 for the 0\%, 5\%, and 10\% nanoparticle-containing mortar bar samples. Comparing these, it was shown that the ordinary mortar exhibited the least damage, with relatively minor salt scaling at the corners (Figure 11(a)). The extent of damage grows with increasing amounts of $\mathrm{TiO}_{2}$ in the mortar, with the maximum damage in case of the $10 \% \mathrm{TiO}_{2}$ 
(Figure 11(c)). For that case, spalling, expansion, and vertical cracking were observed at the corners with expansion and scaling progressing from the corners across the sample faces.
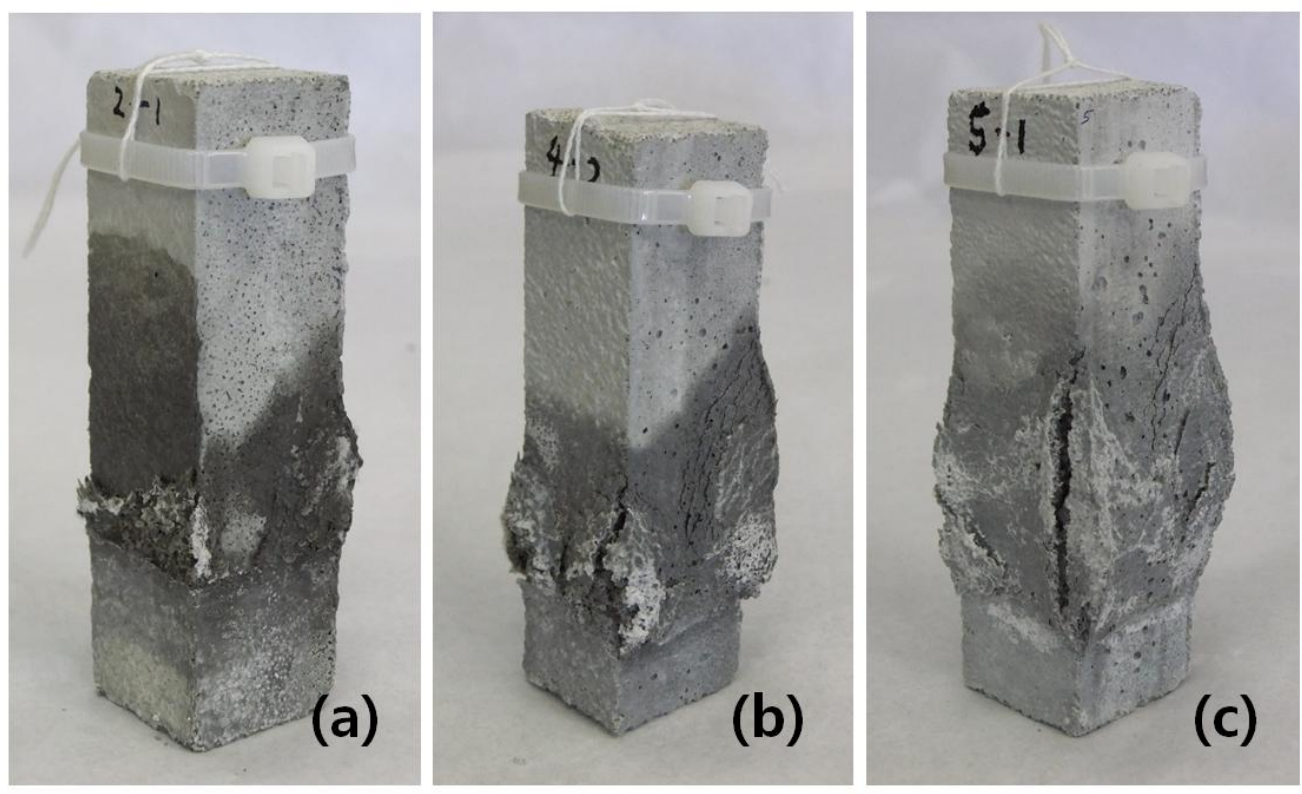

Figure $11-\mathrm{w} / \mathrm{b}=0.50$ samples tested in $15 \% \mathrm{Ca}\left(\mathrm{NO}_{3}\right)_{2}$ solution for 92 days (a) $0 \% \mathrm{TiO}_{2}$, (b) $5 \% \mathrm{TiO}_{2}$, and (c) $10 \% \mathrm{TiO}_{2}$.

Figure 12 shows the deteriorated parts of each of the samples presented in Figure 11 at higher magnification by optical microscopy. The needle-like precipitates of $\mathrm{Ca}\left(\mathrm{NO}_{3}\right)_{2}$ salts were observed in the cracks of all of the samples. It is shown that the length and the extent of the precipitates are greater at higher percentage of $\mathrm{TiO}_{2}$. 

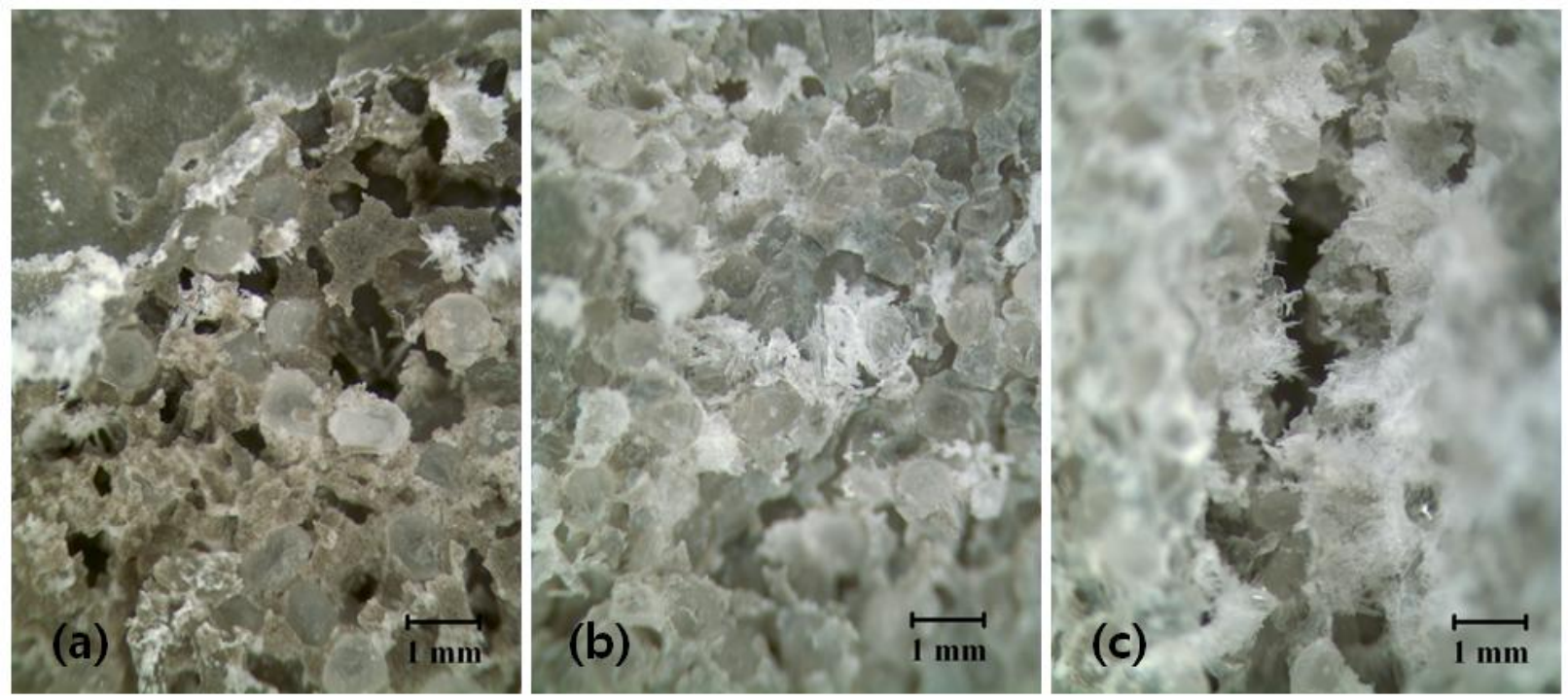

Figure 12 - Damaged surfaces of $\mathrm{w} / \mathrm{b}=0.50$ samples partially immersed in $15 \% \mathrm{Ca}\left(\mathrm{NO}_{3}\right)_{2}$ solution for 92days (a) $0 \%$, (b) $5 \%$, and (c) $10 \%$ nanoparticles.

In order to investigate the possible reasons for the differences in salt scaling damage between varying amounts of nanoparticle use as partial cement replacement, a microstructural evaluation was performed. The surface area and pore size distribution of a hydrated cementitious material are closely related to microstructure development that could potentially explain variations in macroscopic properties, including salt crystallization damage. Nitrogen BET surface area and pore size distribution of the $0 \%, 5 \%$, and $10 \%$ nanoparticle containing cement pastes at $\mathrm{w} / \mathrm{b}=0.50$ were measured after 7 days of curing, using a surface area and porosimetry analyzer (ASAP 2020, Micromeritics, Norcross, GA). Curing conditions and the number of curing days in limewater for these paste samples were the same as the mortar bars used for this study. Here, the three days of successive drying was not applied for the cement pastes in order to eliminate possible variation in drying rate with different nanoparticle dosages. The samples were crushed to pass No. 8 sieve (2.38 mm opening) and retained on No. 16 sieve (1.19 mm opening), and 
were subsequently freeze dried for 3 days. The BET surface area was measured to be $50.3 \mathrm{~m}^{2} / \mathrm{g}$, $66.1 \mathrm{~m}^{2} / \mathrm{g}$, and $84.5 \mathrm{~m}^{2} / \mathrm{g}$ for the $0 \%, 5 \%$, and $10 \%$ samples respectively, showing an increased surface area with higher $\mathrm{TiO}_{2}$ use rates. The pore size distribution was calculated using the Barrett, Joyner, Hallenda (BJH) method and the cumulative pore area distribution and cumulative pore volume distribution results are shown in Figure 13 (a) and (b) respectively.
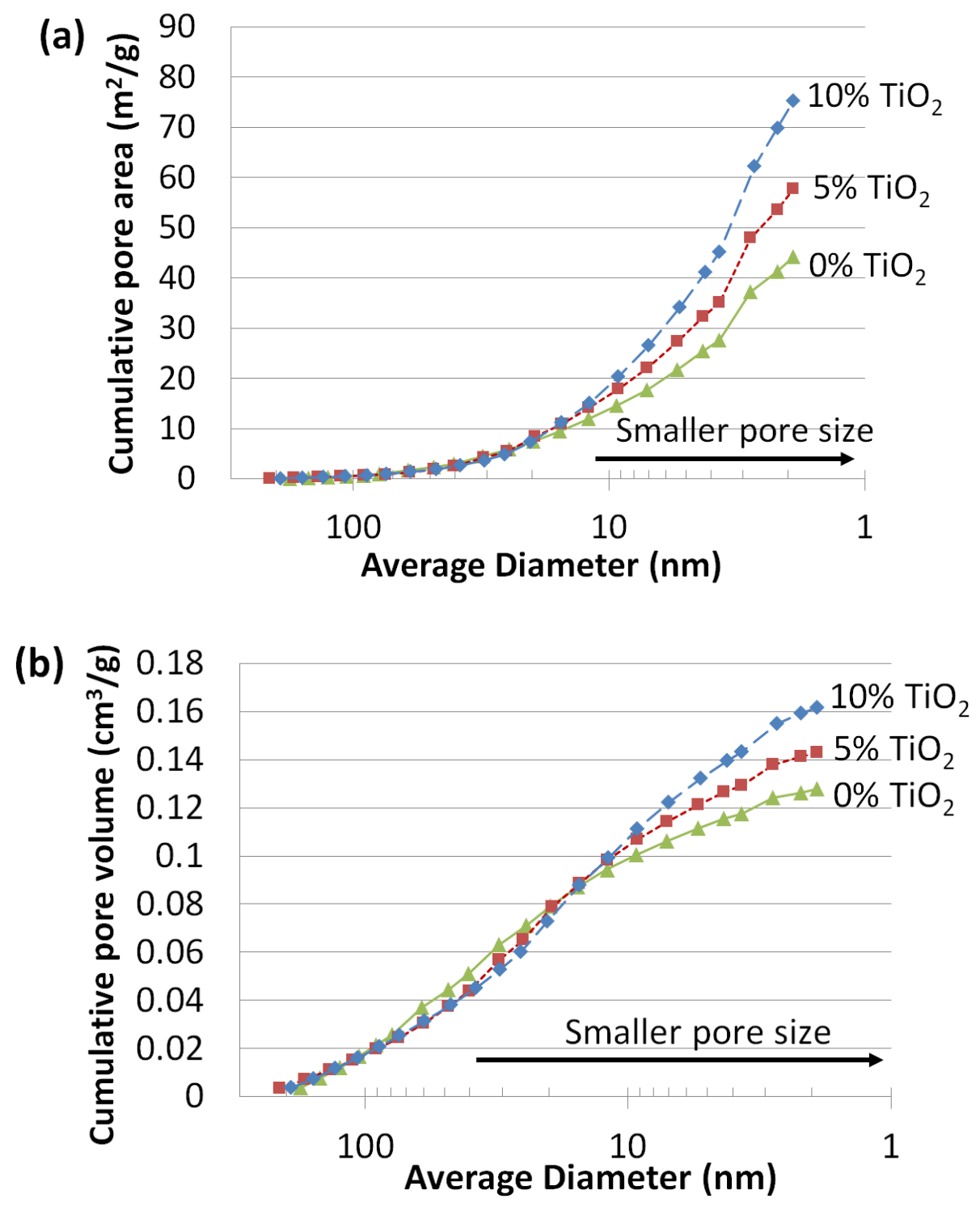

Figure 13 - (a) Cumulative pore area distribution and (b) Cumulative pore volume distribution of $\mathrm{w} / \mathrm{b}=0.50$ paste samples at 7 days of curing at $0 \%, 5 \%$, and $10 \%$ nanoparticles replacement by weight of cement. 
From these results, it was found that higher $\mathrm{TiO}_{2}$ replacement rates resulted in greater pore volume and pore size refinement, evident by an increase in the BET surface area and the amount of pores smaller than $10 \mathrm{~nm}$. This demonstrates that the use of high surface $\mathrm{TiO}_{2}$ nanoparticles altered the microstructure of cement pastes. Here, it is important to note that despite the reduction in cement content, the volume of larger pores are not increased, suggesting that permeability is not increased nor is strength expected to be decreased. It is generally understood that micropores - capillary voids smaller than 50nm - do not negatively influence strength and impermeability [20]. Moreover, smaller pores are likely to be discrete and would decrease permeability, and thus flux, of a salt solution.

Relating these results to the salt crystallization theory proposed by Scherer, where smaller pores are more susceptible to high crystallization pressure than large pores [1], provides a likely mechanism for the increased damage observed with increasing nanoparticle content. These results suggest that the denser microstructure, characterized by a greater volume of very small pores $(<10 \mathrm{~nm})$, developed by higher rates of nanoparticle use could have led to greater salt crystallization damage. This suggests that salts can crystallize in nano-sized pores, which could influence the integrity of bulk cementitious materials. Crystallization in nanopores has been predicted by molecular dynamics simulations, where models show stable $\mathrm{NaCl}$ crystals form above $2 \mathrm{~nm}$ pore width [21] and ice crystallizes in 3nm diameter pores [22]. Even if salt crystallization begins in relatively larger pores, as the crystal growth progresses into smaller pore spaces, pressures will grow larger. This suggests that samples with similar strengths and 
permeabilities could exhibit different resistance to salt crystallization, depending on the extent of pore size refinement.

\section{CONCLUSIONS}

The effect of pore structure on salt crystallization damage of cement-based materials was experimentally investigated. Pore structure of mortar bar samples was modified by varying water-to-binder ratio and by replacing cement with varying amounts of $\mathrm{TiO}_{2}$ nanoparticles. The samples were partially exposed to three different salt solutions: $15 \% \mathrm{Ca}\left(\mathrm{NO}_{3}\right)_{2}, 30 \% \mathrm{Ca}\left(\mathrm{NO}_{3}\right)_{2}$, and $15 \% \mathrm{Na}_{2} \mathrm{SO}_{4}$. Based on the results of this study, the following conclusions are drawn.

- Calcium nitrate salts can induce substantial crystallization damage in a relatively short time to mortar bars when low RH $(\leq 35 \pm 3 \%)$ is maintained. The calcium nitrate salts were identified in two forms $-\mathrm{Ca}\left(\mathrm{NO}_{3}\right)_{2} \cdot 2 \mathrm{H}_{2} \mathrm{O}$, and $\mathrm{Ca}\left(\mathrm{NO}_{3}\right)_{2} \cdot 4 \mathrm{H}_{2} \mathrm{O}$. Also, another nitrate compound, $\mathrm{Ca}(\mathrm{OH}) \mathrm{NO}_{3}\left(\mathrm{H}_{2} \mathrm{O}\right)$, was found, suggesting a potential reaction between the ingressing salt and calcium hydroxide in cementitious paste. However, the effect of $\mathrm{Ca}(\mathrm{OH}) \mathrm{NO}_{3}\left(\mathrm{H}_{2} \mathrm{O}\right)$ formation during salt ingress is not well known and further research is required, calcium nitrate salts appear to be a good candidate solution for accelerated laboratory testing to assess potential for damage by physical salt attack.

- The samples with higher w/b experienced more severe salt crystallization damage. This was attributed to 1) increased connectivity of capillary pore structure and 2) decreased strength at higher $w / b$. The increased porosity and permeability of higher $w / b$ is believed 
to increase connectivity of pore structure and increase flux of salt solutions that provide more salts. The higher porosity also negatively affects strength. Here, the effect of higher w/b and thus increased connectivity of capillary pore structure and decreased strength outweighs the potential relief of decreased crystallization pressure due to larger pore sizes at higher $\mathrm{w} / \mathrm{b}$. These results reinforce the knowledge that salt crystallization damage could be mitigated by lowering w/b in cement-based materials.

- The samples exposed to higher concentration of $\mathrm{Ca}\left(\mathrm{NO}_{3}\right)_{2}$ salt solution experienced more severe salt crystallization damage. This indicates that higher concentration of salt solution resulted in higher level of salt crystallization, leading to more severe damage. Also, longer duration of exposure to salt solution increases the extent of damage, because salt crystallization and accumulation increase with time.

- At a given $\mathrm{w} / \mathrm{b}$, the samples containing higher amounts of $\mathrm{TiO}_{2}$ nanoparticles exhibited greater salt crystallization damage. The higher nanoparticles replacement rate resulted in greater pore area and pore volume at pore diameter less than $10 \mathrm{~nm}$. This suggests that salts can crystallize in nano-sized pores, and suggests that pore size refinement induced by nanoparticle use makes porous materials more susceptible to salt crystallization damage. This indicates that samples with similar strength could lead to different salt crystallization resisting performance depending on the extent of pore size refinement.

These observations demonstrate that pore structure strongly affects the extent of salt crystallization damage and that these effects can be examined relatively rapidly in the laboratory 
through partial immersion in calcium nitrate salt solution. These observations show that a w/b of 0.40 or lower would be most appropriate for construction with cement-based materials in saltladen environments. When using nanoparticles, the lowest effect replacement rates are recommended to maintain resistance to salt crystallization damage.

\section{ACKNOWLEDGEMENTS}

This material is based upon work supported by the National Science Foundation under Grant No.

CMMI-0825373. Any opinions, findings, and conclusions or recommendations expressed in this material are those of the authors and do not necessarily reflect the views of the National Science Foundation.

\section{REFERENCES}

[1] Scherer, G.W., "Stress from crystallization of salt", Cement and Concrete Research, Vol. 34, No. 9, 2004, pp. 1613-1624.

[2] Valenza, J.J. and G.W. Scherer, "A review of salt scaling: I. Phenomenology", Cement and Concrete Research, Vol. 37, No. 7, 2007, pp. 1007-1021.

[3] Chatterji, S. and N. Thaulow, "Unambiguous demonstration of destructive crystal growth pressure", Cement and Concrete Research, Vol. 27, No. 6, 1997, pp. 811-816.

[4] Thaulow, N. and S. Sahu, "Mechanism of concrete deterioration due to salt crystallization", Materials Characterization, Vol. 53, No. 2-4, 2004, pp. 123-127.

[5] Idorn, G.M., Concrete progress : from antiquity to third millennium. 1997, London :: Thomas Telford.

[6] Haynes, H., et al., "Salt weathering distress on concrete exposed to sodium sulfate environment", ACI Materials Journal, Vol. 105, No. 1, 2008, pp. 35-43.

[7] Haynes, H., et al., "Salt weathering of concrete by sodium carbonate and sodium chloride", ACI Materials Journal, Vol. 107, No. 3, 2010, pp. 258-266.

[8] Valenza, J.J. and G.W. Scherer, "A review of salt scaling: II. Mechanisms", Cement and Concrete Research, Vol. 37, No. 7, 2007, pp. 1022-1034.

[9] Linnow, K., L. Halsberghe, and M. Steiger, "Analysis of calcium acetate efflorescences formed on ceramic tiles in a museum environment", Journal of Cultural Heritage, Vol. 8, No. 1, 2007, pp. 44-52. 
[10] Ottosen, L.M. and I. Rorig-Dalgard, "Electrokinetic removal of $\mathrm{Ca}\left(\mathrm{NO}_{3}\right)_{2}$ from bricks to avoid salt-induced decay", Electrochimica Acta, Vol. 52, No. 10, 2007, pp. 3454-3463.

[11] Dei, L., M. Mauro, and G. Bitossi, "Characterisation of salt efflorescences in cultural heritage conservation by thermal analysis", Thermochimica Acta, Vol. 317, No. 2, 1998, pp. 133-140.

[12] "Physicochemical aspects of the deliquescence of calcium nitrate and its implications for wall painting conservation", Studies in Conservation, Vol. 37, No. 4, 1992, pp. 217-227.

[13] Cook, R.A. and K.C. Hover, "Mercury porosimetry of hardened cement pastes", Cement and Concrete Research, Vol. 29, No. 6, 1999, pp. 933-943.

[14] Jayapalan, A.R., B.Y. Lee, and K.E. Kurtis, "Can nanotechnology be 'green'? Comparing efficacy of nano and microparticles in cementitious materials", Cement and Concrete Composites, Vol. 36, No. 0, 2013, pp. 16-24.

[15] Stokes, R.H. and R.A. Robinson, "Standard Solutions for Humidity Control at $25^{\circ}$ C", $^{\prime \prime}$ Industrial \& Engineering Chemistry, Vol. 41, No. 9, 1949, pp. 2013-2013.

[16] Lee, B.Y. and K.E. Kurtis, "Influence of $\mathrm{TiO}_{2}$ Nanoparticles on Early $\mathrm{C}_{3} \mathrm{~S}$ Hydration", Journal of the American Ceramic Society, Vol. 93, No. 10, 2010, pp. 3399-3405.

[17] Lee, B.Y., A.R. Jayapalan, and K.E. Kurtis, "Effects of nano- $\mathrm{TiO}_{2}$ on properties of cement-based materials", Magazine of Concrete Research, Vol. 65, No. 21, 2013, pp. 1293-1302.

[18] Toutanji, H.A. and T. El-Korchi, "The influence of silica fume on the compressive strength of cement paste and mortar", Cement and Concrete Research, Vol. 25, No. 7, 1995, pp. 1591-1602.

[19] Flatt, R.J., "Salt damage in porous materials: how high supersaturations are generated", Journal of Crystal Growth, Vol. 242, No. 3-4, 2002, pp. 435-454.

[20] Mehta, P.K. and P.J.M. Monteiro, Concrete: microstructure, properties, and materials. 2nd ed. College custom series. 1993, New York McGraw-Hill.

[21] Kalcher, I. and Dzubiella, "NaCl crystallization in apolar nanometer-sized confinement studied by atomistic simulations", Physical Review E, Vol. 88, No. 6, 2013, pp. 062312.

[22] Moore, E. B., Llave, E., Welke, K., Scherlis, D. A., Molinero, V., "Freezing, melting and structure of ice in a hydrophilic nanopore", Physical Chemistry Chemical Physics, Vol. 12, No. 16, 2010, pp. 4124-4134. 